\title{
The "Well-Being" and "III-Being" of Online Impulsive and Compulsive Buying on Life Satisfaction: The Role of Self-Esteem and Harmony in Life
}

Journal of Macromarketing

$1-18$

(C) The Author(s) 2021

(c) (i)

Article reuse guidelines:

sagepub.com/journals-permissions DOI: $10.1|77 / 0276| 4672 \mid 104875$ | journals.sagepub.com/home/jmk

(S)AGE

\author{
Svein Ottar Olsen' (D), Nguyen Huu Khoi ${ }^{2}$ (D), and Ho Huy Tuu ${ }^{2}$
}

\begin{abstract}
The antecedents and implications of shopping are relevant to impulsive and compulsive buying behaviour, because both tendencies can be harmful to an individual's well-being, ill-being, and for society as regards overconsumption and sustainability. Most studies investigating either impulsive or compulsive buying have used different definitions and operationalisations of the two constructs. It is unclear whether impulsive buying and compulsive buying are both parts of shopping ill-being. This study defines and measures impulsive buying tendency (IBT) and compulsive buying tendency (CBT) in terms of distinctive core features: impulse versus urge or addiction. It compares their antecedents and consequences in one integrated empirical study, with self-esteem (SE) an antecedent, and satisfaction with life (SWL) a consequence of these two shopping tendencies. To our knowledge it is also the first study to investigate how harmony in life (HIL) is associated with the relationship between SE and IBT/CBT. A survey of 384 consumers indicates that online IBT and CBT differ from a bottom-up consumer well-being perspective. IBT contributes to life satisfaction, but CBT does not. Positive and negative SE have opposite effects on online IBT and CBT, confirming that both can act as self-regulation mechanisms. HIL moderates the relationship between SE and IBT/CBT.
\end{abstract}

\section{Keywords}

impulsive buying tendencies, compulsive buying tendencies, negative and positive self-esteem, satisfaction with life, harmony in life

\section{Introduction}

From a consumer well-being perspective, industry should develop and market goods and services that provide pleasure, joy, excitement and happiness (Hirschman 1992; Ridgway, Kukar-Kinney and Monroe 2008; Rook 1987), and improve life satisfaction and well-being in a way that minimises negative side effects of shopping on individuals, their families or society (Sirgy and Lee 1996). Individual, social and environmental implications mean that macromarketers and quality-of-life researchers have paid particular attention to issues related to consumers shopping behaviour or tendencies. In the area of macromarketing, and from a bottom-up spillover theory of satisfaction (Sirgy 2012), subjective well-being (SWB) is an important consequence of consumer shopping well-being and shopping ill-being (Ekici et al. 2017). These positive and negative implications of shopping are also relevant to impulsive and compulsive buying behaviour (Iyer et al. 2019) because both tendencies can be harmful for individuals well-being and for society in the area of overconsumption and sustainability (Iyer et al. 2019; Ridgway, Kukar-Kinney and Monroe 2008). Impulse buying accounts for between $30 \%$ and $50 \%$ of selfreported purchases, and almost $40 \%$ of all online expenditure (Fook and McNeill 2020).
IBT and CBT are both the results of various individual, social and environmental differences (Chan, Cheung and Lee 2017; Iyer et al. 2019; Müller, Mitchell and de Zwaan 2015). One theoretical approach to studying the antecedents and consequences of impulsive and compulsive buying is from the perspective of self-regulation (Baumeister 2002), and sees them as a struggle between hunting for pleasure and the happy life, and forgetting sorrows and avoiding bad things (Verplanken and Sato 2011). The tendency and motivation of individuals to regulate their thinking, feelings or behaviour to avoid discomfort is well documented in the different context of addiction (e.g., Gökçearslan et al. 2016). Probably the most commonly noted personality characteristic of impulsive and compulsive spenders is low self-esteem (SE). SE is traditionally defined as an individual's net global evaluation of

'School of Business and Economics, UiT - The Arctic University of Norway, Tromsø, Norway

${ }^{2}$ Economics Faculty, Nha Trang University, Nha Trang, Vietnam

\section{Corresponding Author:}

Svein Ottar Olsen, Professor, School of Business and Economics, UiT - The Arctic University of Norway, N-9037 Tromsø, Norway.

E-mail: svein.o.olsen@uit.no 
their own worth (Rosenberg 1965), and has been contradictory measured and related to both IBT (Bandyopadhyay 2016; Silvera, Lavack and Kropp 2008; Thompson and Prendergast 2015) and CBT (Desarbo and Edwards 1996; Ridgway, Kukar-Kinney and Monroe 2008; Roberts 1998; Roberts, Manolis and Pullig 2014). This study extends the existing literature within the self-regulation approach by taking a twodimensional approach to SE (i.e., positive vs. negative selfesteem; Donnellan, Ackerman and Brecheen 2016) to explore both impulsive and compulsive online shopping tendencies.

This study contributes to the consumer well-being literature by investigating whether and how harmony in life (HILS; Kjell et al. 2015) is associated with online IBT and ICT. HIL is a construct that captures the degree of balance between positive and negative feelings and behaviour (Delle et al. 2016). From a selfregulation perspective this study suggests that HIL moderates the effects of positive versus negative self-esteem on both IBT and CBT. Life balance is noted as highly relevant to the understanding of consumer well-being (Sirgy and Lee 2018), but to our knowledge, HIL has not been examined in previous empirical studies of IBT and CBT.

There is increasing debate about the distinctions and similarities between impulsive buying tendency (IBT) and compulsive buying tendency (CBT) (Amos, Holmes and Keneson 2014; Darrat, Darrat and Amyx 2016; Yi 2013). The problem with past research is that most previous studies investigated either impulsive or compulsive buying tendencies, or merged items from both into one composite construct. IBT and CBT have also been operationalised in different ways in studies that have looked at both together (Darrat, Darrat and Amyx 2016; Flight, Beatty and Rountree 2012; Yi 2013). It is also unclear whether impulsive buying and compulsive buying are both parts of shopping ill-being. For example, Lee et al. (2014) defines shopping ill-being experiences as 'the degree to which consumers experience impulse buying and/or compulsive buying in shopping through overspending time, effort, and money' (p. 33). Theoretical and operational definitions of IBT and CBT are of vital importance for what those constructs do and do not refer to, the similarities and differences between them and other constructs in the field, and may cause invalid conclusions about possible antecedents or negative versus positive consequences (MacKenzie 2003; Nunnaly and Bernstain 1994). This applies also in macromarketing because the aggregated consequences of the individual consumer shopping experiences can have significant positive and/or negative consequences for families, friends, business communities, and in society as a whole (Iyer et al. 2019; Lee et al. 2014; Sigry and Lee 1996). In the same way, it is important to understand if and how individual antecedents influence IBT/CBT (e.g., personality, values, attitudes, preferences, and behavioural tendencies) to perform both private and public interventions caused by individuals' shopping tendencies. Thus, this study contributes to the well-being literature by defining IBT and CBT in terms of their core features and by distinguishing between impulse and urge or addiction, and measuring and examining both tendencies in a single sample.
Finally, the enormous growth of internet shopping is highly relevant for understanding online impulsive and compulsive buying because it enables people to make purchases at anytime, anywhere, if the urge strikes (Chan, Cheung and Lee 2017; Leong, Jaafar and Ainin 2018; Wells, Parboteeah and Valacich 2011; Wu, Chiu and Chen 2020; Zhang et al. 2017), and undoubtedly affects consumer well-being (Dittmar, Long and Bond 2007; Tian et al. 2018; Zheng et al. 2020). Because this study was carried out in Vietnam, it also addresses the need for more non-Western research on (online) impulsive and compulsive buying tendencies (Amos, Holmes and Keneson 2014; He, Kukar-Kinney and Ridgway 2018).

\section{Consumer Well-Being and Satisfaction with Life}

Hedonism, pleasure, fun, enjoyment, fantasy, arousal, sensory stimulation, variety, novelty, surprise and other facets of positive psychology are important to consumer motivation for shopping (Alba and Williams 2013). From this perspective, shopping is an important source of shopping well-being (Mohammad and Es-Haghi 2017), consumer well-being (Sirgy et al. 2011) and general pleasure and subjective well-being (Ekici et al. 2017). Evaluations of individuals general subjective well-being and global life-satisfaction judgements are based on different theoretical approaches (Sirgy 2012). One theoretical approach is the distinction between top-down effects of personality, bottom-up effects of life circumstances and experiences in different life domains, as well as a combination of both (Andrews and Withey 1976; Diener 1984; Payne and Schimmack 2020). The assumption that the pleasure of shopping contributes to general life happiness and well-being are based on the "bottom-up spillover theory of life satisfaction" (Lee et al. 2014; Sirgy 2012). Affective and cognitive experiences of different life spheres or domains (e.g., shopping and leisure activities, family, home, job, education, economic situations etc.) are stored and organised in the memory in a hierarchy of pleasure, satisfaction and feelings (Andrews and Withey 1976). Life satisfaction is at the top of the "domain satisfaction" hierarchy. From this perspective, whether and how shopping and buying contributes to life satisfaction depends on its relative importance and contribution compared with the other domain-specific life spheres.

Within the shopping and buying life sphere, we find studies suggesting that not all forms of shopping (e.g., utilitarian or obligation) contribute positively to shopping well-being (El Hedhli, Zourrig and Chebat 2016; Mohammad and Es-Haghi 2017), or that the relationship between shopping well-being and general subjective well-being is mediated or moderated by other theoretical or contextual variables. For example, El Hedhli, Chebat and Sirgy (2013) argue that the image of shopping malls contributes to shopping well-being by providing individuals with an assortment of shops, contributes to social well-being by providing positive social interactions, to leisure well-being through entertainment, and to community well-being by providing a meeting space for individuals to socialise and experience a sense of community. The experiences and attributes that form shopping 
satisfaction or well-being directly, and general subjective wellbeing indirectly, however, differ between retail, mall and on-line experiences (Çikrıkci 2016; El Hedhli, Chebat and Sirgy 2013; Manolis and Roberts 2012). This study explored how individual general SWB is related to IBT and CBT in an online context.

Consumer well-being can be associated with different facets or domain of individuals life included shopping (Sirgy 2012). Research on general well-being has been driven from two main perspectives (Ryan and Deci 2001). The hedonic approach focuses on happiness and defines well-being in term of pleasure attainment and pain avoidance. The eudaimonic approach focuses on meaning and self-realization and defines general well-being in terms of the degree to which a person is fully functioning. From a hedonistic perspective (Biswas-Diener, Kashdan and King 2009), the most widely used definition of SWB is that proposed by Diener et al. (1985) for overall SWL, which is often measured using the Satisfaction with Life Scale (SWLS). Diener et al. (1985) described SWL as an overall well-being construct based on a positive, cognitive evaluation of all aspects of a person's life. Other constructs related to well-being include happiness, a meaningful life, emotional wellbeing (Baumeister et al. 2013) and psychological well-being, or eudaimonia (Disabato et al. 2016). Because SWL is used extensively to assess individual general well-being, and also because it has rarely been used in previous studies of impulsive (Silvera, Lavack and Kropp 2008) and compulsive (Manolis and Roberts 2012) shopping tendencies, this study adopts SWL (Diener et al. 1985 ) to explore the similarities and differences in consequences between IBT and CBT.

\section{Online Impulsive and Compulsive Buying}

Compulsive buying is suggested to be different from impulsive buying because it relates to an 'inability to control the urge' (Faber et al. 1995, p. 297) and 'leads to extreme negative circumstances' (Ridgway, Kukar-Kinney and Monroe 2008, p. 131). While a utilitarian or emotional motive is an important antecedent of impulsive buying (Iyer et al. 2019), compulsive purchases are made not to obtain utility, but to manage the buyer's emotional state through previously experienced means (Sneath, Lacey and Kennett-Hensel 2008). Despite this, IBT and CBT are occasionally discussed together as purchase behaviours (Iyer et al. 2019; Kwak et al. 2006; Tarka 2019; Zafar et al. 2019). Using overlapping definitions of IBT and CBT in empirical research may hide differences and demonstrate close correlations between the two constructs (e.g., 0.75; Shoham, Gavish and Segev 2015).

There are various definitions of impulsive and compulsive shopping constructs, and several assessment formats are available, ranging from single item to multi-dimensional scales (Manolis and Roberts 2012; Sharma, Sivakumaran and Marshall 2014; Verplanken and Sato 2011). In the consumer behaviour literature, impulsive buying is associated with pleasure, excitement, fun, enjoyment and hedonically-motivated buying behaviour (Hirschman 1992; Rook 1987), whereas compulsive buying is seen as an addiction and associated with guilt, harm and the darker side of consumer behaviour (Darrat, Darrat and Amyx 2016; Flight, Beatty and Rountree 2012; Ridgway, Kukar-Kinney and Monroe 2008). The rich and varied accounts of impulsive and compulsive buying are also sources of confusion, inconsistency and discrepancies in research findings (Verplanken and Sato 2011), and compulsive behaviour is used synonymously with habit, dependence, addiction, and excessive, compulsive or problematic use (Wang and Lee 2020).

Impulsive buying behaviour can be defined as a sudden or immediate purchase, made with no pre-shopping intention and motivated by a powerful and persistent urge to buy immediately (Rook and Fisher 1995). Common to almost all conceptualisations of both online and offline impulse buying are that it is unplanned, unreflective and spontaneous (Chan, Cheung and Lee 2017). This study defines IBT in terms of several core features: buying spontaneously, without planning or thinking, and based on how one feels at the moment of decision (Chan, Cheung and Lee 2017; Ridgway, Kukar-Kinney and Monroe 2008). Compulsive buying is seen as chronic, excessive, and repetitive behaviour, an uncontrollable obsession or a coping mechanism (He, KukarKinney and Ridgway 2018; Kukar-Kinney, Scheinbaum and Schaefers 2016). Müller, Mitchell and de Zwaan (2015, p. 132) describe compulsive buying as 'overpowering urges to buy that are experienced as irresistible and senseless'.

This study follows the advice of Ridgway, Kukar-Kinney and Monroe (2008) to define CBT on the basis of the following core features: the urge to shop, an obsession with shopping (being a 'shopaholic') and the importance of shopping (Andreassen et al. 2015), rather than impulsive, spontaneous, unreflective or unplanned behaviour-the core features of IBT. We do not include several possible positive (e.g., mood modification or feeling happy) and negative (e.g., guilt, conflict, stress, economic problems) associations or regulation mechanisms (antecedents or consequences) in our definition, as these would make it more difficult to compare IBT and CBT. We also define both forms of shopping as general, stable behavioural tendencies that apply to a range of products and services (Ridgway, Kukar-Kinney and Monroe 2008), and are rooted in personality and broadly independent of time and context (Verplanken and Sato 2011). Evidence indicates that personality- and value-like constructs explain and predict general behaviour better, in the long term, than domain-specific values and personality traits (Fleeson and Noftle 2009).

Our definitions offer some advantages. Firstly, different approaches to compulsive buying have encouraged the development of more complex and multidimensional constructs (Maraz, Griffiths and Demetrovics 2016 including shopping addiction (Andreassen et al. 2015). For example, Ridgway, Kukar-Kinney and Monroe (2008) developed a compulsive buying scale with two dimensions: impulsive buying and obsessive-compulsive buying. The latter dimension is considered to represent more extreme behaviour, including additional thoughts and preoccupations, and an 'obsessive-compulsive urge to buy' in order to reduce anxiety, but does not involve 
psychiatric disorder and consequences such as financial harm or damage to family. Secondly, drawing a clear distinction between IBT and CBT has proved difficult, because although many compulsive buyers frequently shop on impulse, most impulsive buyers are not compulsive buyers (Yi 2013).

\section{Correlates Between Impulsive and Compulsive Buying}

Many self-report scales and measures of compulsive and impulsive buying refer to impulsiveness, compulsion and other related individual or external features. The correlations between impulse and compulsive buying have varied in the few studies that have measured both constructs in the same study. The correlation between IBT and CBT has varied from above 0.70 (Japutra, Ekinci and Simkin 2017; Shoham, Gavish and Segev 2015) to 0.60 in Yi (2013), 0.35 in Flight, Beatty and Rountree (2012) and as low as 0.18 in Darrat, Darrat and Amyx (2016). Our definitions, which are based on the core features of impulsive and compulsive (online) buying, are expected to establish a clearer distinction between these two phenomena.

At least two different approaches to the relationship between impulsive and compulsive buying are suggested in the literature. Some previous studies have argued that compulsive buying is an extreme form of impulsive buying, and that the two occupy different positions on a continuum, but that compulsive buying may have more negative consequences than impulsive buying (Darrat, Darrat and Amyx 2016; Ridgway, Kukar-Kinney and Monroe 2008). For example, d'Astous (1990) contended that IBT and CBT are positioned along a continuum of 'urgency to buy' and that repeated impulsive purchases are an early sign of, or trigger for, compulsive buying behaviour. The same view was taken by Raab et al. (2011) and Darrat, Darrat and Amyx (2016), who suggested that repeated impulsive buying represents a loss of self-control that leads, ultimately, to an uncontrollable buying addiction or compulsive buying. Support for this approach comes from a study by Zhang et al. (2017), who reported that CBT is frequently linked to symptoms of depression, and is positively correlated with impulsivity and other impulse control or dependence disorders (see also O'Guinn and Faber 1989). The threshold at which impulsive buying becomes compulsive remains an open question (Ridgway, Kukar-Kinney and Monroe 2008).

An alternative approach focuses on the underlying external state (e.g., cues in the retail environment) and internal or individual differences (e.g., personality traits, personal values) that distinguish impulsive and compulsive buying behaviour (Rook 1987; Thompson and Prendergast 2015; Yi 2013). As such, if online IBT and CBT are separate constructs they should show different patterns of correlation with individual traits, internal states, social expectations and environmental cues. Some previous studies have proposed that online impulsive buying is primarily motivated by external triggers (e.g., cues in the online retail environments), whereas online compulsive buying is primarily motivated by internal triggers (e.g., tension and pressure to buy) (Chan, Cheung and Lee
2017). Considerable effort has been devoted to identifying and discussing antecedent and consequential constructs and factors related to impulsive (for a review, please see Chan, Cheung and Lee 2017) and compulsive buying (for a review, please see Maraz, Griffiths and Demetrovics 2016). For example both IBT and CBT have been correlated with positive and negative affect (Flight, Beatty and Rountree 2012; Mueller et al. 2010; Thompson and Prendergast 2015), self-control, shame and guilt (Yi 2013), subjective well-being and selfesteem/liking (Silvera, Lavack and Kropp 2008), mood and self-identity (Moulding et al. 2017), sensation seeking or variety seeking (Olsen et al. 2016; Sharma, Sivakumaran and Marshall 2014), materialism (Otero-López et al. 2011), selfcongruence (Japutra, Ekinci and Simkin 2017), and personal value dimensions (Shoham, Gavish and Segev 2015).

It is hard to draw conclusions about the similarities and differences between online IBT and CBT, as very few studies have measured both in the same sample. The varying definitions and range of assessment tools for both tendencies also make comparison difficult. For example, it has been argued that impulse buying is enjoyable and should be positively associated with positive affect (Darrat, Darrat and Amyx 2016; Flight, Beatty and Rountree 2012), but Verplanken et al. (2005) suggested that impulsive buying should be associated with negative affect, because - according to self-regulation theory - it is a means of reducing negative feelings. As previously noted, this study contributes to the literature by extending previous research on how individual differences in self-worth/SE (e.g., Silvera, Lavack and Kropp 2008; Thompson and Prendergast 2015) are related to, or self-regulated by, IBT and CBT, and whether and how HIL (Kjell et al. 2015) moderates these relationships. We also explain the similar or different consequences of IBT and CBT for SWL. In the next sections we discuss the core construct relationships with IBT and CBT in an online shopping environment.

\section{Buying Tendencies and Satisfaction with Life}

Whether and how IBT and CBT directly affect or are associated SWB is not well documented in the literature. From a selfregulation perspective (Higgins 1997), but also from a consumer life satisfaction perspective and that of the bottom-up spillover theory of life satisfaction (Ekici et al. 2017; Sirgy 2012), individuals go shopping to both achieve pleasure and avoid pain. Because impulsive buying is important behaviour in shopping for pleasure, excitement and leisure, both off-line (Iyer et al. 2019) and on-line (Chan, Cheung and Lee 2017), it is reasonable to expect a positive relationship between IBT and SWB. For example Herabadi, Verplanken and van Knippenberg (2009) found that impulsive shoppers experienced positive emotions (exited, enthusiastic, feeling an urge, and happy) at the time and place of their actual purchase behaviour. When consumers achieve psychological pleasure and satisfaction by shopping, for example on the internet, they will tend to increase their shopping frequency, which in turn can lead to overuse and addiction. In such a scenario, the pleasure of 
shopping (on impulse) can over time turn into shopping addiction (CBT) with negative consequences on SWB.

From a self-regulation perspective where impulse-buying is performed as means to avoid negative psychological states or traits, IBT should be negatively associated with SWB. This is partly confirmed in one study. Silvera, Lavack and Kropp (2008) found that the cognitive component of IBT was negatively associated with SWB $(-0.15)$, while the affective component was unrelated. In a meta-analytic review, however, Iyer et al. (2019) found a positive relationship between an impulse buying tendency and both positive and negative mood states, and that the relationship between IBT and negative mood was stronger than for positive mood. However, it is also possible to argue that consumers who are satisfied with their lives do not need to shop (by impulse) as a means to achieve happiness and satisfaction in their general life. Many other drivers of SWL outside the shopping domain can compensate for shopping as a means of consumer pleasure or pain. Inconsistencies can also be explained by the definitions and content of the assessment of IBT (Sharma, Sivakumaran and Marshall 2014). Negative items associated with impulsive buying measures may cause negative relationships with SWL. Despite the inconsistent findings and arguments about the relationship between IBT and SWL (e.g., general happiness), this study suggests:

\section{$H_{1}$ : Online IBT has a positive association with SWL.}

As noted above, compulsive buying can be defined as an extreme form of impulsive buying (e.g., Darrat, Darrat and Amyx 2016), or as a distinct construct with different antecedents and consequences (Faber et al. 1995; Rook 1987; Verplanken and Sato 2011). Several formal definitions of CBT use negative consequences (e.g., guilt, conflict, shopaholic, stress, economic problems, extreme suffering) to explain the construct (Desarbo and Edwards 1996; Faber et al. 1995; Ridgway, Kukar-Kinney and Monroe 2008). Research in both psychiatry (e.g., Müller, Mitchell and de Zwaan 2015) and marketing (e.g., Mrad and Cui 2020) explain CBT as a form of addictive behaviour in line with alcoholism, internet use, gambling disorder, and substance use, among others.

The variety of research disciplines and the variety of definitions for CBT make it difficult to compare research about IBT and CBT, as well as consider their relationships with other constructs (Manolis and Roberts 2012). If, for example, shopping addiction (e.g., Andreassen et al. 2015) is assessed as a multidimensional construct with tens of items rather than more focal one-dimensional definitions and few core items (e.g., Ridgway, Kukar-Kinney and Monroe 2008), then comparisons are hard to evaluate. However, in the very few studies that we are aware of, testing the CBT and SWL relationship has resulted in some inconsistent findings. For example, Otero-López et al. (2011) found a highly significant negative correlation (-0.31) between addictive buying and life-satisfaction. This was confirmed by Zhang et al. (2017) using a scale that included both antecedents (e.g., a way of facing stress) and consequences (e.g., post-purchase guilt). In a recent study, Mrad and Cui
(2020) did not confirm any significant relationship between compulsive buying and life happiness.

From a behavioural addiction perspective, the consequences of compulsive shopping are more negative than for IBT. According to a review article by Müller, Mitchell and de Zwaan (2015), compulsive buyers rarely or never use the bought products. Those buyers are more interested in the process of buying, browsing, choosing and ordering, and not in using the products. Consumers buying on impulse can thus experience pleasure from their shopping for products and services not only at the moment they make the purchase, but also later in their buying process, through consumption and postconsumption. Further arguments for a negative relationship between CBT and SWL are found in studies proposing that depression and anxiety are the most important associations with CBT (Zhang et al. 2017), and that compulsive buying accompanies several forms of dysfunctional and psychiatric disorder, such as substance abuse, eating disorders, pathological gambling, internet addiction, alcohol and drug problems (Müller, Mitchell and de Zwaan 2015). Those behaviours are often negatively associated with SWB, happiness and quality of life (e.g., Lei, Chiu and Li 2019). Thus, this study proposes:

\section{$\mathrm{H}_{2}$ : Online CBT is negatively associated with SWL}

\section{Positive and Negative Self-Esteem}

The top-down approach to subjective well-being and global life satisfaction maintains that individuals are predisposed to experience and view SWB as a stable trait or value (Diener 1984). Some people have the potential to be more satisfied, happy and enjoy pleasure and well-being in their lives depending on who they are. Thus, several studies have confirmed significant relationships between SWB and stable individual differences across cultures (Ryan and Deci 2001). SE is used to explain or predict variation in IBT (Bandyopadhyay 2016; Silvera, Lavack and Kropp 2008; Thompson and Prendergast 2015) or CBT (Desarbo and Edwards 1996; Ridgway, Kukar-Kinney and Monroe 2008; Roberts 1998; Roberts, Manolis and Pullig 2014) or in a combination of both IBT and CBT (Ridgway, Kukar-Kinney and Monroe 2008; Shoham, Gavish and Segev 2015). SE is defined as an individual's positive and negative feelings about their value or worth (Rosenberg 1965); it reflects a person's evaluation of their self-worth, self-respect, personal value, skills, abilities and competence (Salerno, Ingoglia and Coco 2017). SE has also been defined as a global cognitive and affective self-evaluation that captures how satisfied one is with oneself. SE is strongly related to individual social belongingness, health, happiness, success and survival (Baumeister et al. 2003). Studies investigating the relationships between SE and IBT or CBT have used different definitions of SE and different tools to assess it. For example, Silvera, Lavack and Kropp (2008) used a two-dimensional SE construct (selfcompetence and self-liking) based on arguments by Tafarodi and Swann (1995); Shoham, Gavish and Segev (2015) used a 'low self-esteem scale' based on work by O'Guinn and Faber 
(1989); Roberts, Manolis and Pullig (2014) used a contingent, one-dimensional SE measure, and Desarbo and Edwards (1996) use a scale developed by Coopersmith (1990).

The Rosenberg Self-Esteem Scale (RES: Rosenberg 1965) is one of the most widely used instruments in the history of psychology and the most widely used measure of SE (McKay, Boduszek and Harvey 2014). This study adopts a conceptual distinction between positive and negative SE as proposed in research in personality psychology (e.g., Donnellan, Ackerman and Brecheen 2016). Individuals with positive selfesteem believe that they possess many desirable traits and qualities, while individuals with negative self-esteem believe that they possess characteristics that others find unappealing (e.g., Richardson, Ratner and Zumbo 2009). This distinction is also supported in a study about impulse buying tendency (Silvera, Lavack and Kropp 2008). The relationships between positive and negative affect and IBT and CBT have been assessed in some studies (Claes and Müller 2017; Thompson and Prendergast 2015). This study extends the existing literature on the relationship between SE and IBT (Bandyopadhyay 2016) and CBT (Ridgway, Kukar-Kinney and Monroe 2008; Roberts 1998) by examining the relationships between both online IBT and online CBT and two aspects (i.e., positive and negative) of SE in a single study.

Verplanken and Sato (2011) suggested that IBT and CBT can be considered a form of self-regulation, and are related to an individual's ability to regulate their thoughts, feelings and behaviours. As such, the traits, states or outcomes (e.g., mood, higher SE, happiness, or well-being) are more likely in line with individual standards (Baumeister et al. 2003). From a trait perspective, one could argue for a positive or negative relationship between SE and shopping tendencies; "When I am sad, shopping makes me happier". The multiple definitions and operationalisations of SE, and IBT and CBT, make it difficult to find consistent results. Some studies have found a positive association between SE and CBT (Ridgway, Kukar-Kinney and Monroe 2008; Roberts, Manolis and Pullig 2014), but SE has also been demonstrated as negatively associated with both IBT (Bandyopadhyay 2016; Verplanken et al. 2005) and CBT (O'Guinn and Faber 1989), and other studies have found no relationship between these variables (Davenport, Houston and Griffiths 2011; Valence, d; stous and Fortier 1988). Andreassen et al. (2015) used the RES (Rosenberg 1965), and found negative correlations between SE and both shopping addiction $(-0.26)$ and compulsive buying $(-0.27)$.

To our knowledge, no study has tested the relationship between SE and IBT/CBT using the most commonly used measure of SE, the RES (Rosenberg 1965), but Silvera, Lavack and Kropp (2008) did use a two-dimensional SE construct (self-competence and self-liking) based on arguments made by Tafarodi and Swann (1995). They found that neither self-competence nor self-liking were related to IBT. Flight, Beatty and Rountree (2012) found that positive and negative affect - defined as context-specific mood states - had opposing relationships with IBT and CBT, but they also found that both IBT and CBT had exactly the same positive correlation $(0.23)$ with feeling an urge to buy during shopping trips. Thompson and Prendergast (2015) found that impulsive buying was not associated with either positive or negative affect, and Bellini, Cardinali and Grandi (2017) found that negative affect was not associated with urge to buy.

Self-regulation is a process by which individuals bring themselves in harmony with relevant goals such as the feeling of pleasure, harmony in life, or SWB. From such a perspective, different forms of shopping and buying behaviour (e.g., self-gifting, buying for others and recreation shopping) can be a route and instrument for maintaining the pleasure of SWB or avoiding or repairing pain. It is, nevertheless, reasonable to expect positive relationships between negative SE and online IBT and CBT, because negative $\mathrm{SE}$ is likely to be a particularly powerful source of negative psychological states (O'Guinn and Faber 1989) that might prompt people to buy things in order to obtain psychological relief through self-regulation processes (Verplanken et al. 2005). In contrast, since positive SE is negatively related to negative SE, one would expect individuals with positive SE to show little tendency for impulsive and compulsive behaviours, because they do not need to relieve negative psychological states and their self-gap is positive disconfirmation (i.e., the current self is better than the one they expect). Thus,

$H_{3}$ : Negative SE has a positive association with (a) online IBT and (b) online CBT.

$H_{4}$ : Positive SE has negative association with (a) online IBT and (b) online CBT.

Several studies testing the relationship between SE and IBT/ CBT use a global one-dimensional scale to assess SE (Bandyopadhyay 2016; Ridgway, Kukar-Kinney and Monroe 2008; Roberts, Manolis and Pullig 2014; Shoham, Gavish and Segev 2015). This study postulates that online IBT and CBT have different relationships with negative and positive SE. Specifically, we hypothesise that the associations between CBT and both negative and positive SE would be stronger than those between IBT and these two aspects of SE (i.e., negative and positive), for several reasons. Firstly, impulsive buying could be an early sign of, or trigger for, compulsive buying (Darrat, Darrat and Amyx 2016). In other words, individuals involved in impulsive buying gradually lose control and fall into addiction (Raab et al. 2011), and compulsive buying is described as a peak of impulsive buying (dAstous 1990; Darrat, Darrat and Amyx 2016). Secondly, impulsive buying is a mild form of impulsivity, while compulsive buying is regarded as a severe form of addiction that disrupts everyday functioning (Kwak et al. 2006, p. 61). Negative and positive SE, in a corresponding mechanism, may thus have stronger associations with online CBT than with online IBT. Based on these discussions, our first two hypotheses were as follows:

$H_{5}$ : Negative $\mathrm{SE}$ has a stronger positive association with online CBT than with online IBT.

$H_{6}$ : Positive SE has a stronger negative association with online CBT than with online IBT. 


\section{Harmony in Life and Moderation}

It has been argued, however, that SWL does not represent the full breadth of an individual's cognitive well-being (Garcia, Nima and Kjell 2014). For example, Delle et al. (2010) argued that the SWB construct does not include psychological balance, harmony and expectations of life. In the other words, it fails to reflect a more holistic world view that incorporates a balanced and flexible approach to personal well-being harmony in life (HIL; Kjell et al. 2015; Kjell 2011). The HIL construct includes a more flexible global evaluation of whether one's life is in balance, one's mindfulness and whether one fits into one's social surroundings and is attuned with one's life. HIL has been defined as "the perception of harmony at the inner level, as inner peace, self-acceptance, serenity, a feeling of balance and evenness" (Delle et al. 2010). It has also been described as harmonising different aspects within the world, and playing a role in individual behaviours (Kjell et al. 2015). The inclusion of HIL is important, because the cognitive aspects of HIL, such as selflessness, harmonious adjustment, decentring and psychological flexibility (Dambrun and Ricard 2011; Kjell et al. 2015), stand in contrast to the commonly recognised components of SWL, including self-centeredness, self-enhancement, satisfaction, biased selfinterest, egoism, egocentrism and egotism. A recent study of people in 13 countries found that the terms most frequently used to describe happiness were 'inner harmony' and 'balance' (Delle et al. 2016). We thus include HIL to more fully reflect the breadth of individual SE and self-regulation mechanisms in achieving a higher SWL. As a global construct, HIL differs from the bottom-up spillover theory of life satisfaction where life balance is defined as a balance between how individuals feel in a combination of certain life domains such as work life versus family life (Sirgy and Lee 2018). This study frames balance and harmony in life as individual capacities or motivations to regulate thinking, feeling and behaviour, in order to achieve balance between pleasure and pain or positive and negative self-esteem.

The correlation between SE, SWB and HIL is proposed as relatively high, and is expected to be moderated by an individual's self-control, adjustment and flexibility in order to achieve stable and long-term happiness (Kjell et al. 2015; Kwan, Bond and Singelis 1997). According to the definition above, HIL is also a form of self-regulation mechanism or process (Higgins 1997). It is thus plausible that HIL can moderate the effects of SE on IBT and CBT. To our knowledge, no studies have empirically tested the moderating role of HIL on the relationship between SE and IBT/CBT. Kacen and Lee (2002) found that collectivism (or harmony seeking) could moderate the relationship between self-concept and impulsive buying. This is expected, as HIL is related to non-judgementality, mindful acceptance and psychological flexibility (Kashdan and Rottenberg 2010). Individuals with high levels of mindfulness and psychological flexibility can be described as having peace of mind, cognitive flexibility - qualities of being, allowing and letting be - and wholeness (Kashdan and Rottenberg
2010; Teasdale and Chaskalson 2011a, 2011b). It has been suggested that these characteristics are negatively related to processes leading to impulsive behaviours (e.g., impulsive and compulsive buying) (Claes and Müller 2017; Silvera, Lavack and Kropp 2008; Verplanken et al. 2005; Verplanken and Sato 2011; Zhang et al. 2017).

A happy life seems to entail an intermediate level of SE, but low or high SE can be harmful to maintaining that life (Mruk 2006). This is in line with the self-regulation approach proposed by Verplanken and Sato (2011) regarding impulsive and compulsive buying. They defined seeking pleasure, hedonism, materialism and the pursuit of symbolic values as promotion-focused strategies, and dealing with negative affect, mood, emotional instability, self-control or low SE as prevention-focused strategies (Higgins 1997). There is a fairly strong association between SE and SWB (around 0.50 ), especially in Western cultures, where it is taken for granted that individuals are motivated to feel good about themselves (Diener and Diener 2009). High SE, autonomy, independence, a strong ego and individualism are considered of vital importance for the good life in some cultures, but can be seen as an illusion in other collectivistic cultures. Previous research (e.g., Mruk 2006) has also indicated that extreme SE (i.e., too high or too low SE) could be harmful to an individual's psychology and behaviour. Individuals may thus develop mechanisms, such as happiness or harmony to balance extreme SE and to recover from aversive events due to unintended behaviours (e.g., chronic impulsive buying; Baumeister et al. 2003). Because HIL may be conflicting or dissonant with extreme SE, individuals may seek to reduce this conflict or dissonance by balancing extreme SE, and making it less important to behaviours such as impulsive and compulsive buying. The two final hypotheses are as follows:

$H_{7}$ : The positive effects of negative SE on (a) online IBT and (b) online CBT become weaker when the level of HIL increases.

$H_{8}$ : The negative effects of positive SE on (a) online IBT and (b) online CBT become weaker when the level of HIL increases.

Finally, as mentioned in the introduction above, impulsive buying is considered a rational and beneficial behaviour, while compulsive buying is not (Sneath, Lacey and Kennett-Hensel 2008). Compulsive buying seems to have more negative consequences than impulsive buying (Darrat, Darrat and Amyx 2016; Ridgway, Kukar-Kinney and Monroe 2008), And therefore, the level of dissonance between HIL and extreme SE would be stronger for compulsive buying than for impulsive buying. If hypotheses $\mathrm{H} 7$ and $\mathrm{H} 8$ are supported, it would be interesting to test the additional following hypothesis:

$H_{9}$ : The magnitude of the moderator effects of HIL are stronger for online CBT than for online IBT. 


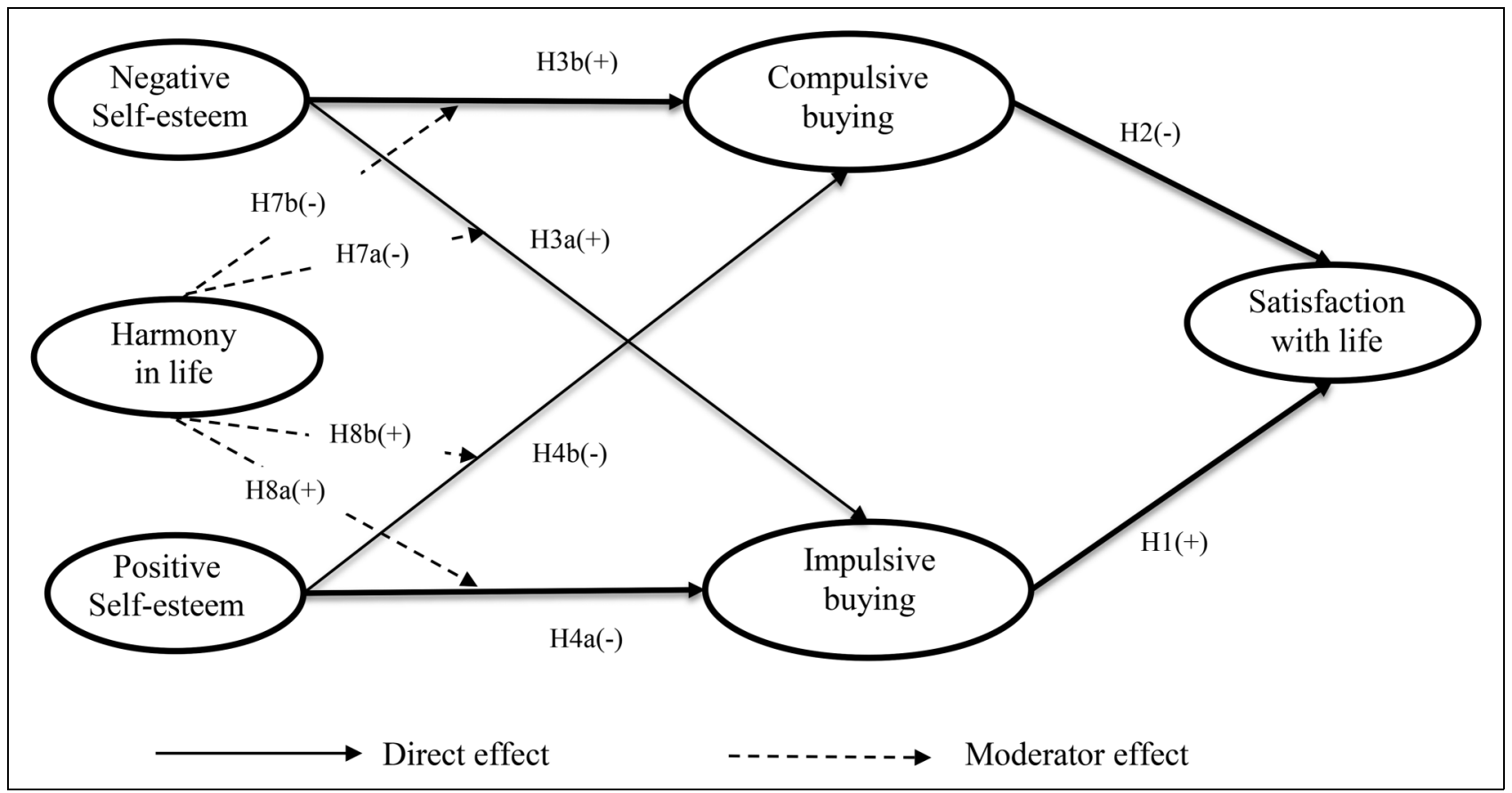

Figure I. The theoretical model.

Figure 1 presents a picture of the theoretical model with the hypotheses, based on the above discussion.

\section{Methods}

\section{Sample}

Data collection was conducted in central Vietnam via a snowball approach using a self-administered questionnaire, to which an online shopping customer introduces their fellow online shopping customers (e.g., friends, relatives, colleagues). The original English version was translated into Vietnamese and then translated back into English by a language instructor. The two English versions of the questionnaire were compared to ensure that the Vietnamese translation was consistent with the original. The Vietnamese questionnaire was pre-tested with 30 students and two university professors whose main research area is consumer behaviour. To minimise response bias, respondents were informed that the study was about their online shopping behaviours. We emphasised that we were interested in the personal opinions of respondents and that there were no right or wrong answers. A total of 350 customers agreed to join a self-administered survey that took a maximum of $10 \mathrm{~min}$ to complete, during summer of 2019. Two cases were rejected because of missing data, and thus a dataset of 348 cases was used for analysis. The typical respondents were female (57.76\%), married $(67.09 \%)$ and had at least graduated from high school (77.00\%). Their average age was 29 years, ranging from 18 to 65 , and their average income per month was about USD 350 .

\section{Measurements}

According to Nunnnaly and Bernstain (1994), specifying the domain of the observables related to a construct and determining the extent to which the observables tend to measure the same thing are the two most important issues in psychometric theory. Failing to adequately define the theoretical approach and conceptual domain of a construct causes problems with what the construct does and does not refer to, the similarities and differences between it and other constructs in the field, and may cause invalid conclusions about relationships (e.g., antecedents and consequences) with other constructs (MacKenzie 2003). Thus, it should be of interest to know if and how IBT and CBT are similar or different constructs to explore their relationships with, for example, consumers' ill-being, well-being, or life satisfaction.

Like Flight, Beatty and Rountree (2012), our aim was to compare the fundamental concept of IBT and CBT. We thus selected the items that best represent or reflect the conceptual definition and description of each core construct. Although this narrow view of IBT and CBT is not ideal in all cases, it appears to be appropriate for the purpose of comparing two core concepts (IBT and CBT). Online IBT was measured using four items: spontaneity, lack of reflection, current feelings, and impulsivity (Ridgway, Kukar-Kinney and Monroe (2008); (Rook and Fisher 1995). Online CBT was defined as the urge to shop, and shopping obsessively was assessed using a total of four items used by previous studies (Faber \& O'Guinn, 1992; Ridgway, Kukar-Kinney and Monroe 2008). The scales used to assess SE (Rosenberg 1965), SWL (Diener et al. 1985) and HIL (Kjell et al. 2015) were unaltered from previous studies. All responses were given using sevenpoint Likert scales (see Appendix A). 


\section{Results}

\section{Reliability and Validity}

The constructs were assessed to ensure internal consistency and convergent and discriminant validity. Cronbach's alpha $(\alpha)$ and composite reliability were used to assess the reliability, and average variance extracted was used to evaluate the convergence validity of the studied constructs. We adopted the Fornell and Larcker criterion (1981) and the HeterotraitMonotrait (HTMT) ratio of the correlation matrix to assess the discriminant validity of the measurement model.

The results, as summarised in Appendix A, demonstrated that all values of $\alpha$ and $C R$ were above 0.70 , indicating that the reliability of the studied constructs was acceptable. All the variances extracted exceeded the recommended threshold of 0.50 , indicating acceptable convergent validity.

As shown in Table 1, the maximum intercorrelation between constructs (0.44) was less than the minimum square root of the $A V E$ s (lowest value 0.73 ), demonstrating that the discriminant validity was acceptable (Fornell and Larcker 1981). The HTMT correlation matrix demonstrated that all intercorrelation coefficients were less than 0.85 , providing further evidence for acceptable discriminant validity.

\section{Common Method Biases}

We assessed common method bias using the common latent factor approach (Podsakoff et al. 2003), as justified for PLS-SEM (Liang et al. 2007). A common latent factor, whose indicators were the items of the studied constructs, was accordingly added to the estimated model. The new model was estimated, and the correlation matrix was examined. The results indicated that the correlation matrix was almost unchanged under the influence of the common latent factor. We thus concluded that common method biases were not problematic in the current research.

\section{Hypothesis Testing}

Research Model Quality. The main results of hypotheses testing are presented in Table 2. Three criteria-the coefficient of determination $\left(R^{2}\right)$, Stone-Geisser $\left(Q^{2}\right)$ and Cohen's Indicator of effect size $\left(f^{2}\right)$-were used to assess research model quality. The estimated results indicated that the research model had an adequate explanatory power, with $R^{2}(\%)$ for SWL of 19.6. The $Q^{2}$ of SWL (0.09) were also greater than 0 , providing further evidence supporting the predictive relevance of the exogenous latent variables. Values of $0.35,0.15$, and 0.02 for Cohen's Indicator $f^{2}$ are considered large, medium and small effects, respectively. The results demonstrated that the effects examined were moderate and weak.

Direct Effects. The results supported H1, showing that IBT has a positive impact on SWL $\left(\beta_{1}=0.37, t=8.42, p<0.001\right)$. However, $\mathrm{H} 2$ was not supported when CBT did not exert a significant effect on SWL $\left(\beta_{2}=-0.07, t=1.58, p>0.05\right)$. A post-hoc test demonstrates that the difference in the strength of those relationships is significant (see Table 3). The results also showed that negative SE has a positive effect on online IBT $\left(\beta_{3 a}=0.10, t=1.81, p<0.1\right)$ and online CBT $\left(\beta_{3 b}=\right.$ $0.26, t=5.33, p<0.001$ ) supporting $\mathrm{H} 3 \mathrm{a}$ and $\mathrm{H} 3 \mathrm{~b}$, respectively. Finally, positive SE has negative effects on online IBT $\left(\beta_{4 a}=\right.$ $-0.19, t=3.46, p<0.01)$ and online CBT $\left(\beta_{4 b}=-0.32\right.$, $t=5.83, p<0.001$ ). Thus, $\mathrm{H} 4 \mathrm{a}$ and $\mathrm{H} 4 \mathrm{~b}$ were supported.

Moderator Effects. The results support two of the proposed moderating effects, rather than four (see Table 2). Hypotheses $\mathrm{H} 7 \mathrm{a}$ and $\mathrm{H} 7 \mathrm{~b}$, that HIL weakens the positive effects of negative SE on online IBT and online CBT, were not supported by the data $\left(\beta_{7 a}=-0.08, t=1.26, p>0.1\right.$ and $\beta_{7 b}=-0.10, t=1.59$, $p>0.1$, respectively). Hypotheses H8a and H8b, that HIL weakens the negative effects of positive $\mathrm{SE}$ on online IBT and online CBT, were supported by the data $\left(\beta_{8 a}=0.17\right.$, $t=2.56, p<0.05$ and $\beta_{8 b}=0.15, t=2.5, p<0.05$, respectively).

The Relative Importance. The procedure proposed by Rodríguez-Entrena, Schuberth and Gelhard (2018) for testing parameter difference in PLS was adopted. Accordingly, in Step 1 , we obtained estimated parameters (i.e., $\beta_{3 a}$ to $\beta_{8 b}$ ) from the PLS estimation. In Step 2, the differences between interested estimated parameters were calculated. Next, we used the bootstrap procedure in PLS to obtain bootstrap estimates of interest parameters. We then calculated the variance of the estimated parameter differences derived from Step 2. Finally (Step 5), we calculated three different bootstrap confidence intervals (CI), including Standard CI, Percentile CI, and Basic CI. If these

Table I. Means, Standard Deviations and Correlations.

\begin{tabular}{|c|c|c|c|c|c|c|c|c|}
\hline Constructs & Mean & $S D$ & I & 2 & 3 & 4 & 5 & 6 \\
\hline 2. HIL & 5.13 & 0.90 & $0.43^{* * *}$ & 0.73 & 0.46 & 0.09 & 0.07 & 0.12 \\
\hline 4. SE-N & 3.69 & 1.42 & $-0.04^{\mathrm{ns}}$ & $-0.03^{\mathrm{ns}}$ & $-0.17^{*}$ & 0.83 & 0.11 & 0.32 \\
\hline 5. IBT & 3.27 & 1.60 & $0.36 * * *$ & $-0.04^{\mathrm{ns}}$ & $-0.26 * *$ & $0.11 *$ & 0.85 & 0.50 \\
\hline 6. CBT & 3.25 & 1.50 & $0.12^{*}$ & $-0.11 *$ & $-0.4 I^{* * * *}$ & $0.30 * * *$ & $0.44 * * *$ & 0.84 \\
\hline
\end{tabular}

Note. The square roots of AVEs are on the diagonal; $* p<0.05 ; * * p<0.01 ; * * * p<0.001$; ${ }^{\text {ns }}$ non-significant; Pearson correlations and Heterotrait-Monotrait ratios are at the lower and upper end of the diagonal, respectively. 
Table 2. Results of Hypotheses Testing.

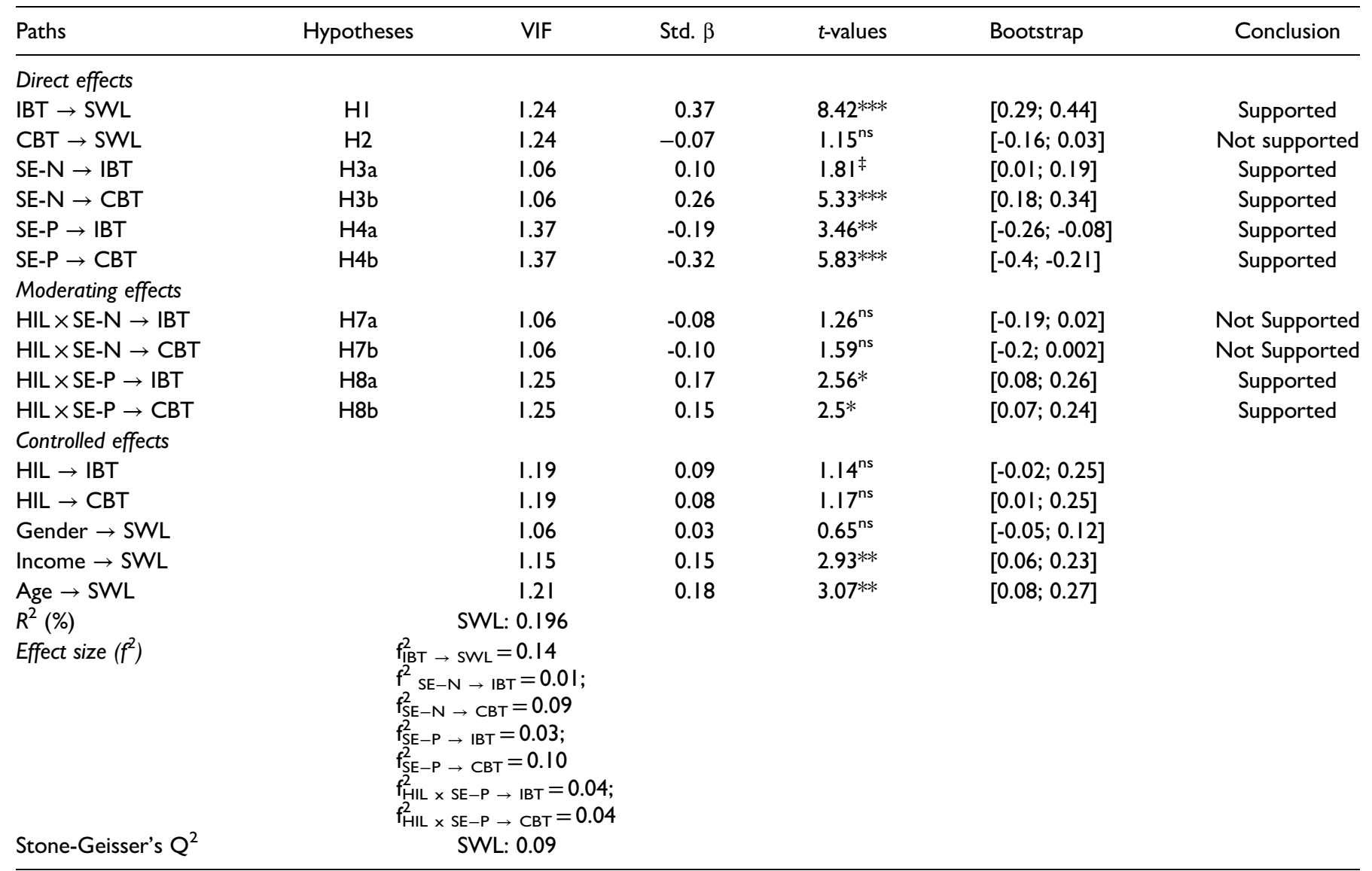

Table 3. Testing the Relative Importance of Direct Effects.

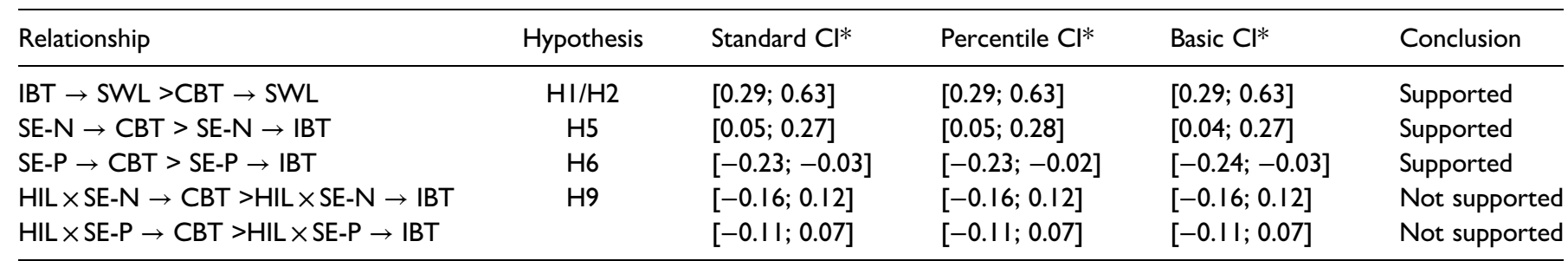

Note: $* p<0.05$

CIs do not contain the value of zero, we can conclude that the corresponding differences between interested estimated parameters is significant.

The test results (see Table 3) showed that 95\% CI derived from the bootstrap procedure, with 5000 sub-samples that did not contain zero. As such, we concluded that hypotheses H5 and H6, regarding the relative importance of direct effects, were supported by the data. In other words, SE (positive and negative) has a stronger effect on online CBT than it does on online IBT. Finally, we expected the moderator effects of HIL to be stronger for CBT than for IBT (H9), however, this hypothesis was not supported because the differences were too small to be significant, with $95 \%$ CIs containing zero.
Controlled Effects. The proposed research model was also used to investigate the controlled effect of gender, income, and age on the evaluation of SWL. The test results indicate that gender did not have a significant relationship with SWL. The two remaining variables, income $(\beta=0.15, t=2.93, p<0.01)$ and age $(\beta=0.18, t=3.07, p<0.01)$, had significant positive relationships with SWL.

\section{Discussion}

This study aimed to extend previous research (e.g., Kukar-Kinney, Scheinbaum and Schaefers 2016; Silvera, Lavack and Kropp 2008; Thompson and Prendergast 2015) by combining a self- 
regulation perspective (Baumeister 2002; Verplanken and Sato 2011) and the bottom-up spillover theory of consumer wellbeing/ill-being (Ekici et al. 2017; Sirgy 2012) in an online context, and by examining the similarities and differences between IBT and CBT. We applied SEM to analyse data from 348 Vietnamese consumers and found that our estimated model had a good fit, and that the constructs investigated had high reliability and validity. IBT are highly positive associated with SWB, but CBT was lightly (not significantly) negatively associated with SWB. The differences between those relationships are significant, however, and thus, we can conclude that IBT and CBT differ in their consequences from a bottom-up consumer well-being perspective. The significant differences in the strengths of the relationships between SE and IBT/CBT indicate that IBT and CBT can be different constructs (antecedents) from a selfregulation perspective.

\section{Theoretical Implications}

The results show that IBT, as a form of shopping well-being, contributes to overall quality of life, but CBT seems to be a possible component of shopping ill-being (Ekici et al. 2017) and makes no contribution toward SWL. This finding confirms that impulsive buying is an important behaviour in the area of shopping for pleasure, excitement and leisure (Chan, Cheung and Lee 2017; Iyer et al. 2019). On the other hand, from the behavioural addiction perspective, we argue, discuss and "nearly" empirically validate the negative impact of CBT on SWL (Müller, Mitchell and de Zwaan 2015). This result is also consistent with arguments that CBT is linked to depression and anxiety (Zhang et al. 2017), and that compulsive buying is associated with some severe forms of dysfunctional and psychiatric disorders (Müller, Mitchell and de Zwaan 2015). This study followed Ridgway, Kukar-Kinney and Monroe (2008) suggestion to use only core features in order to differentiate between impulsive and compulsive buying in a single sample and structural model. We have thus provided a theoretically robust empirical comparison of online IBT and CBT. The current study significantly suggests, from a bottom-up spillover theory of life satisfaction perspective (Sirgy 2012), that online IBT and CBT are distinctive constructs with different patterns of correlation with SWL overall.

Previous studies have adopted SE to explain or predict either IBT or CBT separately (Bandyopadhyay 2016; Desarbo and Edwards 1996; Ridgway, Kukar-Kinney and Monroe 2008; Roberts 1998; Roberts, Manolis and Pullig 2014; Shoham, Gavish and Segev 2015; Thompson and Prendergast 2015). Notwithstanding, these studies have used various conceptualisations of SE (Roberts, Manolis and Pullig 2014; Shoham, Gavish and Segev 2015) and consequently produced inconsistent results (Desarbo and Edwards 1996; Roberts, Manolis and Pullig 2014; Shoham, Gavish and Segev 2015). Some studies found associations between SE and IBT or CBT (Bandyopadhyay 2016; O'Guinn and Faber 1989; Ridgway, Kukar-Kinney and Monroe 2008; Roberts, Manolis and Pullig 2014; Verplanken et al. 2005) whereas others did not
(Davenport, Houston and Griffiths 2011; Valence, d'Astous and Fortier 1988). Our study is distinct from previous studies in extending our understanding of IBT and CBT in the online context by using a two-dimensional model of SE (Ang et al. 2006; Donnellan, Ackerman and Brecheen 2016), and exploring the opposite effects of positive and negative SE (Supple et al. 2012) on online IBT and CBT. From the perspective of self-regulation, different forms of shopping and buying behaviour can be a route and instrument for maintaining the pleasure of SWB or avoiding or repairing pain. We contribute by applying a well-established concept, that negative psychological states are important driving factors, while positive psychological states are barriers behind online IBT and CBT (Claes and Müller 2017; Silvera, Lavack and Kropp 2008; Verplanken and Sato 2011; Zhang et al. 2017). The finding that negative SE has positive effects on online IBT and CBT is consistent with social control theory, which suggests that individuals with negative SE are less able to delay gratification, less tolerant of frustration, and more impulsive (Ang et al. 2006). The negative effects of positive SE on online IBT and CBT can be related to mastery goal orientation (Ang et al. 2006). More specifically, while both online IBT and CBT are positively related to negative SE and negatively associated with positive SE, the relationship between $\mathrm{SE}$ (positive and negative) and online IBT is significantly weaker than that of SE and online CBT. This is expected, as IBT is different from CBT - at least in the strength of the relationships. Thus, compulsive buying will be more favoured by consumers with negative SE, and will not be favoured by consumers with positive SE. This study also contributes to the discussion about whether positive and negative SE are separate constructs (Donnelly et al. 2016) with different significant relationships with shopping tendencies, and explores whether and how IBT/CBT mediate the relationship between SE and SWB.

This study is the first step towards a preliminary understanding of how HIL accounts for online IBT and CBT. By defining HIL as a global individual trait-like construct, we emphasise an alternative from the bottom-up spillover theory of life satisfaction, where life balance is defined as a balance between how individuals feel in a combination of certain life domains, such as work life versus family life (Sirgy and Lee 2018). HIL can thus be a form of self-regulation mechanism or process (Higgins 1997), and exert a moderating effect on the SE IBT/CBT links. This is consistent with previous arguments (e.g., Mruk 2006) that extreme SE could be harmful to individuals from both a psychology and behaviour perspective, and that they thus need to develop mechanisms to balance extreme SE (e.g., harmony) and to recover from "bad" behaviours (e.g., chronic impulsive buying; Baumeister et al. 2003). The moderating effects of HIL on the link between positive SE - IBT and positive SE - CBT are therefore consistent with the conceptualisation of HIL that demonstrates a conflict between HIL and positive SE, thus making positive SE less important to individuals.

We failed, however, to demonstrate that HIL moderates the relationships between negative SE and the two buying 
tendencies. As Vietnam is a collectivist culture, Vietnamese adolescents may not be strongly interested in individualist values such as autonomy, independence, self-orientation, idiocentricism, freedom and self-confidence (Mai et al. 2003). It is possible, therefore, that in our research context, HIL does not have a conflicting relationship with negative SE, and thus, does not moderate its impact on IBT and CBT. Another explanation is that there may be moderator variables that weaken the moderating effects of HIL on the negative SE-IBT/CBT links at the individual level, such as self-control, and other personality traits or personal values. As such, this study provides preliminary evidence of how HIL is related to online IBT/CBT and longitudinal studies should be conducted to corroborate our results. This study supports other ones combining a top-down and bottom-up approach to SWB and global life satisfaction judgement, suggesting that stable individual differences, such as personality, have top-down effect on domain satisfaction, but SWB are formed in a bottom-up process with experiences from different life domains (e.g., Payne and Schimmack 2020). Finally, our controltesting for demographic variables indicated that income and age are positively related to the evaluation of SWL.

Guided by the consumer well/ill-being and bottom-up spillover theory of satisfaction (Ekici et al. 2017; Sirgy 2012; Sirgy, Lee and Rahtz 2007), this study has shown that the way one defines and measures IBT and CBT is important in understanding both their causes and consequences. Negative self-esteem and CBT (addiction) are dysfunctional not only for individuals (ill-being and low SWB) but also for families, friends, and society. In this way, our research helps to shed light on challenges with construct conceptualisation and measurement (MacKenzie 2003) in the context of consumer well-being.

\section{Practical Implications}

The development of the internet and the increasing number of online shoppers makes it likely that impulsive and compulsive buying will become more prevalent. Impulsive shopping may be relatively harmless, but compulsive buying can have serious consequences (Silvera, Lavack and Kropp 2008; Zhang et al. 2017). As impulsive buying is different from compulsive buying from the perspective of positive outcomes in SWL, it is possible to accept marketing strategies fostering impulsive buying but not compulsive buying among consumers. Governments should focus more on addiction and perhaps let impulse be a positive part of consumers' well-being. Treating both of those phenomena as the same issue is not necessarily the most preferable consumer policy.

Firstly, the results demonstrate that individuals with negative psychological states (i.e., negative SE) are more likely to engage in online compulsive buying in order to obtain temporary relief. Policymakers should develop social marketing campaigns integrated in online tools to encourage them to find other approaches to improving their psychological state. For example, convincing messages could be integrated into personalised recommendation systems to send to compulsive buyers. Online technology allows consumer preferences, behaviour, individual characteristics, and other information to be collected in order to identify and categorise consumers "who they are", "what they want", or the like, and then send them messages that best fit their status. It may be effective for consumers who are identified as compulsive buyers, to be reassured that they don't have to buy something to feel good about themselves, or they could be sent slogans such as "Feeling blue? Resist the impulse to buy" (Silvera, Lavack and Kropp 2008).

Secondly, compulsive buyers can be identified through their personal characteristics, namely their negative SE. Online businesses or policymakers could develop early education programs regarding the negative consequences associated with online impulsive and compulsive buying. Government agencies should also promote consumer advocacy groups and set up social intervention programs to encourage consumers to become more selfless and goal-oriented, so that they can be further inoculated against compulsive online buying. Maintaining and boosting positive self-esteem by helping consumers establish positive connections in online social networks and create good feelings about themselves may also be necessary to limit compulsive buying.

Thirdly, the findings show that HIL plays an important, and probably a more controlled, role in decreasing the volume of compulsive buying in an online context. Social marketing campaigns should encourage consumers to pursue harmony in their daily life. For example, there could be campaigns to encourage consumers to share experiences, thoughts, psychological states, knowledge and advice via social media in order to retain a feeling of balance and evenness, achieve inner peace, selfacceptance, serenity, and finally to achieve emotional stability and authentic and durable happiness. Online businesses should also understand the potential sources of HIL so as to control and improve them for a more responsible and ethical business purpose. For example, it may be appropriate to ensure consumer trust by making specific brand promises or offer advice to help them become wise customers, which could keep them in the desired state of HIL.

Finally, our argument suggests that impulsive buying is good for consumers since it facilitates their satisfaction with life. According to the findings, we suggest that for example online retail-managers need to fully understand their potential and current customers, and identify which ones need to improve their self-esteem, because these consumers might use impulsive buying to feel better about themselves and their life. While not investigated in the current study, many well-established studies have suggest that online impulsive buying is primarily motivated by external triggers, for example, customised views, ease of use, social presence, and marketing stimulus (Chan, Cheung and Lee 2017). Managers should thus design comprehensive marketing strategies that foster people's motivation to buy. For example, website design should focus on highly task-relevant cues to foster impulsive buying behaviour (Parboteeah, Valacich and Wells 2009).

\section{Limitations and Future Research}

This study is not free of limitations. It provides some preliminary evidence that online IBT, and CBT have different 
consequences for an individual's well-being and ill-being, such as their general SWL. However, previous research on IBT and $\mathrm{CBT}$ in an offline context has demonstrated that CBT can be seen as an extreme form of IBT. As such, future research into online and offline impulsive and compulsive buying should extend past studies by explaining how various individual differences (e.g., Big-Five personality traits, personal values, mood) cause IBT/CBT and how it influences their specific emotions, shopping well-being, and, further, their general subjective wellbeing and/or ill-being (e.g., financial consequences, guilt, conflict, stress etc.). Such research would improve our understanding of online impulsive and compulsive buying, and their antecedents and consequences, in an integrated nomological network of established psychological constructs. Including both online and offline IBT/CBT in one integrated study in order to explore whether those two contexts provide different or similar results should be considered in future research.

Secondly, this study only provides preliminary evidence about the relationships between HIL and IBT and CBT in an online context. Future studies should investigate whether other individual difference factors (e.g., trait impulsiveness, self-control, and emotional stability) are related to HIL. Is HIL a trait that individuals can control to achieve self-regulation and SWB? Since the current literature also suggests that impulsive and compulsive buying are different from the SWL perspective, but are similar from the perspective of SE, it would be interesting to investigate the temporal relationship between them, through longitudinal studies.

Thirdly, although our sample provided informative data on online buying behaviour and tendencies, future studies should expand the range of groups investigated, and use experimental designs or longitudinal studies to eliminate common method bias and elucidate the causal nature of the relationships. For example, in this study we suggest the $\mathrm{SE} \rightarrow \mathrm{IBT} / \mathrm{CBT} \rightarrow$ SWB causal relationships. Some studies have suggested that well-being or general affect is an antecedent of IBT or CBT (Silvera, Lavack and Kropp 2008; Thompson and Prendergast 2015). Other studies propose that compulsion causes impulses (Leong, Jaafar and Ainin 2018; Zhang et al. 2017), or that impulses cause the urge to buy (Darrat, Darrat and Amyx 2016; Zafar et al. 2019). Future studies should thus consider causal relationships and be more consistent in the specific (core items) or general items they use to define and measure IBT and CBT as psychological and behavioural constructs. For example can the use of multidimensional scales of CBT/IBT (e.g., Andreassen et al. 2015; He, KukarKinney and Ridgway 2018; Sharma, Sivakumaran and Marshall 2014) or integrated scales of both constructs (e.g., Horváth and Adıgüzel 2018; Manolis and Roberts 2012; Ridgway, Kukar-Kinney and Monroe 2008) be problematic in their associations with antecedents and consequences of those different shopping tendencies. Finally, this study focuses on general shopping tendencies. Online impulse and compulsive shopping vary across website stimuli, products, services, brands and price (e.g., Chan, Cheung and Lee 2017). Future research should include issues on those issues.
Associate Editor:M. Joseph Sirgy

\section{Declaration of Conflicting Interests}

The author(s) declared no potential conflicts of interest with respect to the research, authorship, and/or publication of this article.

\section{Funding}

This work was funded by the Vietnam National Foundation for Science and Technology Development (NAFOSTED) under Grant No. 502.022018.311 .

\section{ORCID iDs}

Svein Ottar Olsen (iD https://orcid.org/0000-0001-9507-5846

Nguyen Huu Khoi (iD https://orcid.org/0000-0002-6253-7263

\section{Supplemental Material}

Supplemental material for this article is available online.

\section{References}

Alba, Joseph W. and Elanor F Williams (2013), "Pleasure Principles: A Review of Research on Hedonic Consumption", Journal of Consumer Psychology, 23 (1), 2-18.

Amos, Clinton, Gary R. Holmes, and William C Keneson (2014), "A Meta-Analysis of Consumer Impulse Buying", Journal of Retailing and Consumer Services, 21 (2), 86-97.

Andreassen, C. S., M. D. Griffiths, S. Pallesen, R. M. Bilder, T. Torsheim, and E Aboujaoude (2015), "The Bergen Shopping Addiction Scale: Reliability and Validity of A Brief Screening Test”, Frontiers in Psychology, 6 (September), 1-11.

Andrews, Frank M and Stephen B. Withey (1976). Social Indicators of Well-Being: Americans' Perceptions of Life Quality, New York: Plenum Press.

Ang, Rebecca P, Marion Neubronner, Su-Ann Oh, and Victoria Leong (2006), "Dimensionality of Rosenberg's Self-Esteem Scale among Normal-Technical Stream Students in Singapore", Current Psychology, 25 (2), 120-31.

Bandyopadhyay, Nirmalya (2016), "The Role of Self-Esteem, Negative Affect and Normative Influence in Impulse Buying: A Study From India", Marketing Intelligence \& Planning, 34 (4), 523-39.

Baumeister, Roy F (2002), "Yielding to Temptation: Self-Control Failure, Impulsive Purchasing, and Consumer Behavior", Journal of Consumer Research, 28 (4), 670-6.

Baumeister, Roy F, Jennifer D Campbell, Joachim I Krueger, and Kathleen D Vohs (2003), "Does High Self-Esteem Cause Better Performance, Interpersonal Success, Happiness, or Healthier Lifestyles?", Psychological Science in the Public Interest, 4 (1), 1-44.

Baumeister, Roy F., Kathleen D. Vohs, Jennifer L. Aaker, and Emily N Garbinsky (2013), "Some key Differences Between A Happy Life and A Meaningful Life", The Journal of Positive Psychology, 8 (6), 505-16.

Bellini, Silvia, Maria Grazia Cardinali, and Benedetta Grandi (2017), "A Structural Equation Model of Impulse Buying Behaviour in Grocery Retailing”, Journal of Retailing and Consumer Services, 36 (May), 164-71. 
Biswas-Diener, Robert, Todd B. Kashdan, and Laura A King (2009), "Two Traditions of Happiness Research, not two Distinct Types of Happiness", The Journal of Positive Psychology, 4 (3), 208-11.

Chan, Tommy K. H., Christy M. K. Cheung, and Zach W. Y Lee (2017), "The State of Online Impulse-Buying Research: A Literature Analysis", Information \& Management, 54 (2), 204-17. Çikrıkci, Özkan (2016), "The Effect of Internet use on Well-Being: Meta-Analysis", Computers in Human Behavior, 65 (December), 560-6.

Claes, Laurence and Astrid Müller (2017), "Resisting Temptation: Is Compulsive Buying an Expression of Personality Deficits?", Current Addiction Reports, 4 (3), 237-45.

Coopersmith, S. (1990). SEI: Self-Esteem Inventories, Palo Alto, CA: Consulting Psychologists Press.

Dambrun, Michaël and Matthieu Ricard (2011), "Self-centeredness and Selflessness: A Theory of Self-Based Psychological Functioning and its Consequences for Happiness", Review of General Psychology, 15 (2), 138-57.

Darrat, Aadel A., Mahmoud A. Darrat, and Douglas Amyx (2016), "How Impulse Buying Influences Compulsive Buying: The Central Role of Consumer Anxiety and Escapism", Journal of Retailing and Consumer Services, 31 (July), 103-8.

d'Astous, Alain (1990), "An Inquiry Into the Compulsive side of "Normal" Consumers", Journal of Consumer Policy, 13 (1), 15-31.

Davenport, Kate, James E. Houston, and Mark D Griffiths (2011), "Excessive Eating and Compulsive Buying Behaviours in Women: An Empirical Pilot Study Examining Reward Sensitivity, Anxiety, Impulsivity, Self-Esteem and Social Desirability", International Journal of Mental Health and Addiction, 10 (4), 474-89.

Delle, Antonella Fave, Ingrid Brdar, Teresa Freire, Dianne Vella-Brodrick, and Marié P Wissing (2010), "The Eudaimonic and Hedonic Components of Happiness: Qualitative and Quantitative Findings", Social Indicators Research, 100 (2), 185-207.

Delle, Antonella Fave, Ingrid Brdar, Marié P Wissing, Ulisses Araujo, Alejandro Castro Solano," Teresa Freire, et al. (2016), "Lay Definitions of Happiness Across Nations: The Primacy of Inner Harmony and Relational Connectedness", Frontiers in Psychology, 7 (January), 1-23.

Desarbo, Wayne S and Elizabeth A Edwards (1996), "Typologies of Compulsive Buying Behavior: A Constrained Clusterwise Regression Approach", Journal of Consumer Psychology, 5 (3), 231-62.

Diener, Ed (1984), "Subjective Well-Being”, Psychological Bulletin, 95 (3), 542-75.

Diener, Ed and Marissa Diener (2009), "Cross-cultural Correlates of Life Satisfaction and Self-Esteem". In Culture and Well-Being. Social Indicators Research Series, E. Diener, Ed.. vol 38 (pp. 71-91). Dordrecht: Springer.

Diener, ED, Robert A Emmons, Randy J Larsen, and Sharon Griffin (1985), "The Satisfaction with Life Scale", Journal of Personality Assessment, 49 (1), 71-5.

Disabato, David J, Fallon R Goodman, Todd B Kashdan, Jerome L Short, and Aaron Jarden (2016), "Different Types of Well-Being? A Cross-Cultural Examination of Hedonic and Eudaimonic Well-Being”, Psychological Assessment, 28 (5), 471-82.

Dittmar, Helga, Karen Long, and Rod Bond (2007), "When A Better Self is Only A Button Click Away: Associations Between
Materialistic Values, Emotional and Identity-Related Buying Motives, and Compulsive Buying Tendency Online", Journal of Social and Clinical Psychology, 26 (3), 334-61.

Donnellan, M. B., R. A. Ackerman, and C Brecheen (2016), "Extending Structural Analyses of the Rosenberg Self-Esteem Scale to Consider Criterion-Related Validity: Can Composite Self-Esteem Scores be Good Enough?”, Journal of Personality Assessment, 98 (2), 169-77. Donnelly, Grant E, Masha Ksendzova, Ryan T Howell, Kathleen D Vohs, and Roy F Baumeister (2016), "Buying to Blunt Negative Feelings: Materialistic escape From the Self", Review of General Psychology, 20 (3), 272.

Ekici, Ahmet, Joseph Sirgy, M. Lee, Yu Dong-Jin, B. Grace, and Michael Bosnjak (2017), "The Effects of Shopping Well-Being and Shopping ill-Being on Consumer Life Satisfaction", Applied Research in Quality of Life, 13 (2), 333-53.

El Hedhli, Kamel, Jean-Charles Chebat, and M. Joseph. Sirgy (2013), "Shopping Well-Being at the Mall: Construct, Antecedents, and Consequences", Journal of Business Research, 66 (7), 856-63.

El Hedhli, Kamel, Haithem Zourrig, and Jean-Charles Chebat (2016), "Shopping Well-Being: Is it Just A Matter of Pleasure or Doing the Task? The Role of Shopper's Gender and Self-Congruity”, Journal of Retailing and Consumer Services, 31 (July), 1-13.

Faber, Ronald J and Thomas C O'Guinn (1992), “A clinical screener for compulsive buying”, Journal of Consumer Research, 19 (3), 459-469.

Faber, Ronald J, Gary A Christenson, Martina De Zwaan, and James Mitchell (1995), "Two Forms of Compulsive Consumption: Comorbidity of Compulsive Buying and Binge Eating", Journal of Consumer Research, 22 (3), 296-304.

Fleeson, William and Erik E Noftle (2009), "In Favor of the Synthetic Resolution to the Person-Situation Debate", Journal of Research in Personality, 43 (2), 150-4.

Flight, Richard L., Sharon E. Beatty, and Melissa Markley Rountree (2012), "Feeling the Urge: Affect in Impulsive and Compulsive Buying", The Journal of Marketing Theory and Practice, 20 (4), 453-66.

Fook, Lauren Ah and Lisa McNeill (2020), "Click to buy: The Impact of Retail Credit on Over-Consumption in the Online Environment", Sustainability, 12 (18), 1-15. doi:10.3390/su12187322

Fornell, Claes and David F Larcker (1981), "Evaluating Structural Equation Models with Unobservable Variables and Measurement Error", Journal of Marketing Research, 18 (1), 39-50.

Garcia, Danilo, Ali Al Nima, and Oscar NE Kjell (2014), “The Affective Profiles, Psychological Well-Being, and Harmony: Environmental Mastery and Self-Acceptance Predict the Sense of A Harmonious Life", PeerJ, 2 (e259), 1-21. doi:10.7717/peerj.259

Gökçearslan, Şahin, Filiz Kuşkaya Mumcu, Tülin Haşlaman, and Yasemin Demiraslan. Çevik (2016), "Modelling Smartphone Addiction: The Role of Smartphone Usage, Self-Regulation, General Self-Efficacy and Cyberloafing in University Students", Computers in Human Behavior, 63 (October), 639-49.

He, Heping, Monika Kukar-Kinney, and Nancy M Ridgway (2018), "Compulsive Buying in China: Measurement, Prevalence, and Online Drivers", Journal of Business Research, 91 (October), 28-39. Herabadi, Astrid G., Bas Verplanken, and Ad van Knippenberg (2009), "Consumption Experience of Impulse Buying in Indonesia: 
Emotional Arousal and Hedonistic Considerations", Asian Journal of Social Psychology, 12 (1), 20-31.

Higgins, E Tory (1997), "Beyond Pleasure and Pain", American Psychologist, 52 (12), 1280-300.

Hirschman, Elizabeth C (1992), "The Consciousness of Addiction: Toward A General Theory of Compulsive Consumption", Journal of Consumer Research, 19 (2), 155-79.

Horváth, Csilla and Feray Adigüzel (2018), "Shopping Enjoyment to the Extreme: Hedonic Shopping Motivations and Compulsive Buying in Developed and Emerging Markets", Journal of Business Research, 86 (May), 300-10.

Iyer, Gopalkrishnan R., Markus Blut, Sarah Hong Xiao, and Dhruv Grewal (2019), "Impulse Buying: A Meta-Analytic Review”, Journal of the Academy of Marketing Science, 48 (May), 384-404.

Japutra, Arnold, Yuksel Ekinci, and Lyndon Simkin (2017), "Self-congruence, Brand Attachment and Compulsive Buying", Journal of Business Research, 99 (June), 456-63. doi:10.1016/j. jbusres.2017.08.024

Kacen, Jacqueline J and Julie Anne Lee (2002), "The Influence of Culture on Consumer Impulsive Buying Behavior", Journal of Consumer Psychology, 12 (2), 163-76.

Kashdan, T. B. and J Rottenberg (2010), "Psychological Flexibility as A Fundamental Aspect of Health", Clinical Psychology Review, 30 (7), 865-78.

Kjell, O. N. E., D. Daukantaite, K. Hefferon, and S Sikström (2015), "The Harmony in Life Scale Complements the Satisfaction with Life Scale: Expanding the Conceptualization of the Cognitive Component of Subjective Well-Being", Social Indicators Research, 126 (2), 893-919.

Kjell, Oscar N. E (2011), "Sustainable Well-Being: A Potential Synergy Between Sustainability and Well-Being Research", Review of General Psychology, 15 (3), 255-66.

Kukar-Kinney, Monika, Angeline Close Scheinbaum, and Tobias Schaefers (2016), "Compulsive Buying in Online Daily Deal Settings: An Investigation of Motivations and Contextual Elements", Journal of Business Research, 69 (2), 691-9.

Kwak, Hyokjin, George M Zinkhan, Denise E DeLorme, and Trina Larsen (2006), "Revisiting Normative Influences on Impulsive Buying Behavior and an Extension to Compulsive Buying Behavior: A Case From South Korea", Journal of International Consumer Marketing, 18 (3), 57-80.

Kwan, Virginia SY, Michael Harris Bond, and Theodore M Singelis (1997), "Pancultural Explanations for Life Satisfaction: Adding Relationship Harmony to Self-Esteem", Journal of Personality and Social Psychology, 73 (5), 1038-51.

Lee, Dong-Jin, Grace B. Yu, M. Joseph Sirgy, Ahmet Ekici, Eda Guerel-Astay, and Kenneth D Bahn (2014). "Shopping Well-Being and ill-Being: Toward an Integrated Model", in Handbook of Research on Retailer-Consumer Relationship Development, F. Musso and E. Druica, eds. Pennsylvania, IGI Global, 27-44.

Lei, Hao, Ming Ming Chiu, and Shunyu Li (2019), "Subjective Well-Being and Internet Overuse: A Meta-Analysis of Mainland Chinese Students", Current Psychology, 39 (3), 843-53.
Leong, Lai-Ying, Noor Ismawati Jaafar, and Sulaiman Ainin (2018), “The Effects of Facebook Browsing and Usage Intensity on Impulse Purchase in F-Commerce", Computers in Human Behavior, 78 (January), 160-73.

Liang, Huigang, Nilesh Saraf, Qing Hu, and Yajiong Xue (2007), "Assimilation of Enterprise Systems: The Effect of Institutional Pressures and the Mediating Role of top Management", MIS Quarterly, 31 (1), 59-87.

MacKenzie, Scott B (2003), "The Dangers of Poor Construct Conceptualization," Journal of the Academy of Marketing Science, 31 (3), 323-6.

Mai, Nguyen Thi Tuyet, Kwon Jung, Garold Lantz, and Sandra G Loeb (2003), “An Exploratory Investigation Into Impulse Buying Behavior in A Transitional Economy: A Study of Urban Consumers in Vietnam", Journal of International Marketing, 11 (2), 13-35.

Manolis, Chris and James A Roberts (2012), "Subjective Well-Being among Adolescent Consumers: The Effects of Materialism, Compulsive Buying, and Time Affluence", Applied Research in Quality of Life, 7 (2), 117-35.

Maraz, A., M. D. Griffiths, and Z Demetrovics (2016), "The Prevalence of Compulsive Buying: A Meta-Analysis", Addiction, 111 (3), 408-19.

McKay, M. T., D. Boduszek, and S. A Harvey (2014), "The Rosenberg Self-Esteem Scale: A Bifactor Answer to A two-Factor Question?", Journal of Personality Assessment, 96 (6), 654-60.

Mohammad, Majid Shafiee and Sayyed Mohammad Sadiq Es-Haghi (2017), "Mall Image, Shopping Well-Being and Mall Loyalty", International Journal of Retail \& Distribution Management, 45 (10), 1114-34.

Moulding, Richard, Annie Duong, Maja Nedeljkovic, and Michael Kyrios (2017), "Do you Think That Money can buy Happiness? A Review of the Role of Mood, Materialism, Self, and Cognitions in Compulsive Buying", Current Addiction Reports, 4 (3), 254-61.

Mrad, Mona and Charles Chi Cui (2020), "Comorbidity of Compulsive Buying and Brand Addiction: An Examination of two Types of Addictive Consumption", Journal of Business Research, 113 (May), 399-408.

Mruk, Christopher JJ. (2006). Self-Esteem Research, Theory, and Practice: Toward A Positive Psychology of Self-Esteem (3rd ed.), New York, NY, US: Springer Publishing Company.

Mueller, Astrid, Laurence Claes, James E Mitchell, Steve A Wonderlich, Ross D Crosby, and Martina De Zwaan (2010), "Personality Prototypes in Individuals with Compulsive Buying Based on the Big Five Model", Behaviour Research and Therapy, 48 (9), 930-5.

Müller, A., J. E. Mitchell, and M de Zwaan (2015), "Compulsive Buying", The American Journal on Addictions, 24 (2), 132-7.

Nunnally, Jum C and Ira H Bernstein (1994). Psychometric theory (3rd ed.), New York: McGraw Hill.

O'Guinn, Thomas C and Ronald J Faber (1989), "Compulsive Buying: A Phenomenological Exploration”, Journal of Consumer Research, 16 (2), 147-57.

Olsen, Svein Ottar, Ana Alina Tudoran, Pirjo Honkanen, and Bas Verplanken (2016), "Differences and Similarities Between Impulse Buying and Variety Seeking: A Personality-Based Perspective", Psychology \& Marketing, 33 (1), 36-47. 
Otero-López, José Manuel, Estíbaliz Villardefrancos Pol, Cristina Castro Bolaño, and María José Santiago Mariño (2011), "Materialism, Life-Satisfaction and Addictive Buying: Examining the Causal Relationships", Personality and Individual Differences, 50 (6), 772-6.

Parboteeah, D. Veena, Joseph S. Valacich, and John D Wells (2009), "The Influence of Website Characteristics on A Consumer's Urge to buy Impulsively", Information Systems Research, 20 (1), 60-78.

Payne, Jason W. and Ulrich Schimmack (2020), "Construct Validity of Global Life-Satisfaction Judgments: A look Into the Black box of Self-Informant Agreement", Journal of Research in Personality, 89 (December), 1-10. doi:10.1016/j.jrp.2020.104041

Podsakoff, Philip M, Scott B MacKenzie, Jeong-Yeon Lee, and Nathan P Podsakoff (2003), "Common Method Biases in Behavioral Research: A Critical Review of the Literature and Recommended Remedies", Journal of Applied Psychology, 88 (5), 879-903.

Raab, Gerhard, Christian E Elger, Michael Neuner, and Bernd Weber (2011), "A Neurological Study of Compulsive Buying Behaviour", Journal of Consumer Policy, 34 (4), 401-13.

Richardson, Chris G., Pamela A. Ratner, and Bruno D Zumbo (2009), "Further Support for Multidimensionality Within the Rosenberg Self-Esteem Scale", Current Psychology, 28 (2), 98-114.

Ridgway, Nancy M., Monika Kukar-Kinney, and Kent B Monroe (2008), "An Expanded Conceptualization and A new Measure of Compulsive Buying”, Journal of Consumer Research, 35 (4), 622-39.

Roberts, James A (1998), "Compulsive Buying among College Students: An Investigation of its Antedecents, Consequences, and Implications for Public Policy", Journal Of Consumer Affairs, 32 (2), 295-319.

Roberts, James A, Chris Manolis, and Chris Pullig (2014), "Contingent Self-Esteem, Self-Presentational Concerns, and Compulsive Buying", Psychology \& Marketing, 31 (2), 147-60.

Rodríguez-Entrena, Macario, Florian Schuberth, and Carsten Gelhard (2018), "Assessing Statistical Differences Between Parameters Estimates in Partial Least Squares Path Modeling", Quality \& Quantity, 52 (1), 57-69.

Rook, Dennis W (1987), “The Buying Impulse”, Journal of Consumer Research, 14 (2), 189-99.

Rook, Dennis W and Robert J Fisher (1995), "Normative Influences on Impulsive Buying Behavior", Journal of Consumer Research, 22 (3), 305-13.

Rosenberg, Morris (1965). Society and the Adolescent Self-Image, Rahway, NY: Princeton University Press.

Ryan, Richard M and Edward L Deci (2001), "On Happiness and Human Potentials: A Review of Research on Hedonic and Eudaimonic Well-Being", Annual Review of Psychology, 52 (1), 141-66.

Salerno, Laura, Sonia Ingoglia, and Gianluca Lo Coco (2017), "Competing Factor Structures of the Rosenberg Self-Esteem Scale (RSES) and its Measurement Invariance Across Clinical and non-Clinical Samples", Personality and Individual Differences, 113 (July), 13-9.

Sharma, Piyush, Bharadhwaj Sivakumaran, and Roger Marshall (2014), "Looking Beyond Impulse Buying: A Cross-Cultural and Multi-Domain Investigation of Consumer Impulsiveness", European Journal of Marketing, 48 (5/6), 1159-79.
Shoham, Aviv, Yossi Gavish, and Sigal Segev (2015), "A Cross-Cultural Analysis of Impulsive and Compulsive Buying Behaviors among Israeli and U.S. Consumers: The Influence of Personal Traits and Cultural Values", Journal of International Consumer Marketing, 27 (3), 187-206.

Silvera, David H., Anne M. Lavack, and Fredric Kropp (2008), "Impulse Buying: The Role of Affect, Social Influence, and Subjective Wellbeing”, Journal of Consumer Marketing, 25 (1), 23-33.

Sirgy, M. J. and D. J Lee (2018), The Psychology of Life Balance. In Handbook of Well-Being, E. Diener, S. Oishi, and L. Tay, Eds. Salt Lake City, UT: DEF publishers, 1-18.

Sirgy, M Joseph (2012). The Psychology of Quality of Life: Hedonic Well-Being, Life Satisfaction, and Eudaimonia, Dordrecht, Netherlands: Springer.

Sirgy, M Joseph and Dong-Jin Lee (1996), "Setting Socially Responsible Marketing Objectives", European Journal of Marketing, 30 (5), 20-34.

Sirgy, M. Joseph, Dong-Jin Lee, and Don Rahtz (2007), "Research on Consumer Well-Being (CWB): Overview of the Field and Introduction to the Special Issue", Journal of Macromarketing, 27 (4), 341-9.

Sirgy, M. Joseph, Grace B Yu, Dong-Jin Lee, Shuqin Wei, and Ming-Wei Huang (2011), "Does Marketing Activity Contribute to A Society's Well-Being? The Role of Economic Efficiency", Journal of Business Ethics, 107 (2), 91-102.

Sneath, Julie Z., Russell Lacey, and Pamela A Kennett-Hensel (2008), "Coping with A Natural Disaster: Losses, Emotions, and Impulsive and Compulsive Buying", Marketing Letters, 20 (1), 45-60.

Supple, Andrew J., Jinni Su, Scott W. Plunkett, Gary W. Peterson, and Kevin R Bush (2012), "Factor Structure of the Rosenberg Self-Esteem Scale", Journal of Cross-Cultural Psychology, 44 (5), 748-64.

Tafarodi, Romin W and William B Swann (1995), "Self-linking and Self-Competence as Dimensions of Global Self-Esteem: Initial Validation of A Measure", Journal of Personality Assessment, 65 (2), 322-42.

Tarka, Piotr (2019), "Influence of Materialism on Compulsive Buying Behavior: General Similarities and Differences Related to Studies on Young Adult Consumers in Poland and US", Journal of International Consumer Marketing, 32 (3), 243-67.

Teasdale, John D. and Michael Chaskalson (2011b), "How Does Mindfulness Transform Suffering? II: The Transformation Ofdukkha", Contemporary Buddhism, 12 (1), 103-24.

Teasdale, John D. and Michael Chaskalson (2011a), "How Does Mindfulness Transform Suffering? I: The Nature and Origins Ofdukkha", Contemporary Buddhism, 12 (1), 89-102.

Thompson, Edmund R. and Gerard P Prendergast (2015), "The Influence of Trait Affect and the Five-Factor Personality Model on Impulse Buying", Personality and Individual Differences, 76 (April), 216-21.

Tian, Y., S. Zhang, R. Wu, P. Wang, F. Gao, and Y Chen (2018), "Association Between Specific Internet Activities and Life Satisfaction: The Mediating Effects of Loneliness and Depression", Frontiers in Psychology, 9 (July), 1181. doi:10. 3389/fpsyg.2018.01181 
Valence, Gilles, Alain d'Astous, and Louis Fortier (1988), "Compulsive Buying: Concept and Measurement", Journal of Consumer Policy, 11 (4), 419-33.

Verplanken, Bas, Astrid G. Herabadi, Judith A. Perry, and David H Silvera (2005), "Consumer Style and Health: The Role of Impulsive Buying in Unhealthy Eating", Psychology \& Health, 20 (4), 429-41.

Verplanken, Bas and Ayana Sato (2011), “The Psychology of Impulse Buying: An Integrative Self-Regulation Approach”, Journal of Consumer Policy, 34 (2), 197-210.

Wang, Chuang and Matthew K. O Lee (2020), "Why we Cannot Resist our Smartphones: Investigating Compulsive use of mobile sns From A Stimulus-Response-Reinforcement Perspective", Journal of the Association for Information Systems, 21 (1), 175200.

Wells, John D, Veena Parboteeah, and Joseph S Valacich (2011), "Online Impulse Buying: Understanding the Interplay Between Consumer Impulsiveness and Website Quality", Journal of the Association for Information Systems, 12 (1), 32-56.

Wu, Ing-Long, Mai-Lun Chiu, and Kuei-Wan Chen (2020), "Defining the Determinants of Online Impulse Buying Through A Shopping
Process of Integrating Perceived Risk, Expectation-Confirmation Model, and Flow Theory Issues", International Journal of Information Management, 52 (June), 1-12. doi:10.1016/j. ijinfomgt.2020.102099

Yi, Sunghwan (2013), "Heterogeneity of Compulsive Buyers Based on Impulsivity and Compulsivity Dimensions: A Latent Profile Analytic Approach", Psychiatry Research, 208 (2), 174-82.

Zafar, Abaid Ullah, Jiangnan Qiu, Ying Li, Jingguo Wang, and Mohsin Shahzad (2019), "The Impact of Social media Celebrities' Posts and Contextual Interactions on Impulse Buying in Social Commerce", Computers in Human Behavior, 115 (February), 1-14. doi:10.1016/j.chb.2019.106178.

Zhang, C., J. S. Brook, C. G. Leukefeld, M. De La Rosa, and D. W Brook (2017), "Compulsive Buying and Quality of Life: An Estimate of the Monetary Cost of Compulsive Buying among Adults in Early Midlife", Psychiatry Research, 252 (June), 208-14.

Zheng, Yueli, Xiujuan Yang, Qingqi Liu, Xiaowei Chu, Qitong Huang, and Zongkui Zhou (2020), "Perceived Stress and Online Compulsive Buying among Women: A Moderated Mediation Model", Computers in Human Behavior, 103 (February), 13-20.

\section{Appendix A: Constructs and indicators}

\begin{tabular}{|c|c|c|c|c|}
\hline Constructs and indicators & $\begin{array}{l}\text { Factor } \\
\text { loadings }\end{array}$ & $\begin{array}{l}\text { Cronbach's } \\
\text { Alpha }\end{array}$ & $\begin{array}{l}\text { Composite reliability } \\
\text { (CR) }\end{array}$ & $\begin{array}{l}\text { Variance extracted } \\
\text { (AVE) }\end{array}$ \\
\hline Satisfaction with life (SWL) & & 0.80 & 0.85 & 0.53 \\
\hline In most ways, my life is close to my ideal & 0.69 & & & \\
\hline The conditions of my life are excellent & 0.76 & & & \\
\hline I am satisfied with my life & 0.60 & & & \\
\hline So far, I have gotten the important things I want in life & 0.81 & & & \\
\hline If I could live my life over, I would change almost nothing & 0.77 & & & \\
\hline Harmony in life (HIL) & & 0.80 & 0.85 & 0.53 \\
\hline My lifestyle allows me to be in harmony & 0.75 & & & \\
\hline Most aspects of my life are in balance & 0.66 & & & \\
\hline I am in harmony & 0.83 & & & \\
\hline I accept the various conditions of my life & 0.64 & & & \\
\hline I fit in well with my surroundings & 0.75 & & & \\
\hline Positive self-esteem (SE-P) & & 0.82 & 0.87 & 0.58 \\
\hline On the whole, I am satisfied with myself & 0.71 & & & \\
\hline I take a positive attitude toward myself & 0.88 & & & \\
\hline I feel that I have a number of good qualities & 0.82 & & & \\
\hline I am able to do things as well as most other people & 0.74 & & & \\
\hline $\begin{array}{l}\text { I feel that I'm a person of worth, at least on an equal plane } \\
\text { with others }\end{array}$ & 0.63 & & & \\
\hline Negative self-esteem (SE-N) & & 0.89 & 0.92 & 0.70 \\
\hline I certainly feel useless at times & 0.77 & & & \\
\hline I feel I do not have much to be proud of & 0.90 & & & \\
\hline I wish I could have more respect for myself & 0.87 & & & \\
\hline All in all, I am inclined to feel that I am a failure & 0.77 & & & \\
\hline At times I think I am no good at all & 0.85 & & & \\
\hline Impulsive buying (IBT) & & 0.87 & 0.91 & 0.72 \\
\hline I often buy things online spontaneously & 0.85 & & & \\
\hline I often buy things online without thinking & 0.87 & & & \\
\hline
\end{tabular}




\section{Appendi A (continued)}

\begin{tabular}{lcccc}
\hline Constructs and indicators & $\begin{array}{l}\text { Factor } \\
\text { loadings }\end{array}$ & $\begin{array}{l}\text { Cronbach's } \\
\text { Alpha }\end{array}$ & $\begin{array}{l}\text { Composite reliability } \\
\text { (CR) }\end{array}$ & $\begin{array}{l}\text { Variance extracted } \\
\text { (AVE) }\end{array}$ \\
\hline I buy things online according to how I feel at the time & 0.85 & & & 0.91 \\
I consider myself an online impulse purchaser & 0.83 & 0.86 & & 0.70 \\
Compulsive buying (CBT) & 0.78 & & \\
I often spend more online than I can afford & 0.85 & & \\
I consider myself a online 'shopaholic' & 0.91 & & \\
Much of my life is centered around online shopping & 0.81 & & \\
I spend a lot of time thinking of or planning online & & & \\
shopping/buying &
\end{tabular}

Notes. All factor loadings are significant at $p<0.00$ I. 